\title{
Avaliação de um programa de suplementação alimentar
}

\author{
Manoel Romeu Gutierrez, ${ }^{1}$ Heloisa Bettiol ${ }^{1}$ \\ e Marco Antonio Barbieri ${ }^{1}$
}

RESUMO O objetivo do presente estudo foi avaliar o impacto de um programa de suplementação alimentar sobre o crescimento de crianças desnutridas com menos de 5 anos no município de Guariba, estado de São Paulo, Brasil. A amostra foi constituída por 469 crianças desnutridas freqüentes em um programa de suplementação alimentar da Secretaria de Estado da Saúde. As crianças foram subdivididas em quatro grupos, segundo o tempo de freqüência no programa: no grupo 1, as crianças freqüentavam o programa há 12 meses; no grupo 2, entre 12 e 24 meses; no grupo 3, de 24 a 36 meses; e no grupo 4, há mais do que 35 meses. Foram calculados os percentis de peso e altura por idade e peso por altura de cada criança. Para avaliar o impacto do programa, foram construídas curvas de referência para o perfil antropométrico, baseadas nas variações esperadas dos percentis da população. As mudanças observadas em cada grupo foram analisadas estatisticamente (McNemar). Nos grupos 1 e 2 houve recuperação do peso e adequação do peso por altura para as crianças mais severamente desnutridas; no grupo 3 houve manutenção do peso por altura e uma discreta tendência de recuperação do peso, que foi revertida no grupo 4, no qual o peso das crianças foi baixo para a altura. O programa de suplementação alimentar minimizou temporariamente os déficit nutricionais severos, porém não foi suficiente para a recuperação e manutenção do crescimento.

Com base em dados de estudos nacionais transversais representativos da população de menores de 5 anos, aproximadamente $43 \%$ das crianças que vivem em países em desenvolvimento têm comprometimento da altura para a idade. Na América Latina, onde a situação é mais favorável, a prevalência da desnutrição calórico-protéica (baixa altura para a idade e baixo peso para a

\footnotetext{
Universidade de São Paulo, Faculdade de Medicina de Ribeirão Preto, Departamento de Puericultura e Pediatria, Ribeirão Preto, Brasil. Correspondência e pedidos de separatas devem ser enviados para Manoel Romeu Gutierrez no seguinte endereço: Departamento de Puericultura e Pediatria, Faculdade de Medicina de Ribeirão Preto, Universidade de São Paulo, Avenida Bandeirantes 3900, CEP 14049-900, Ribeirão Preto, SP, Brasil. Fone/ fax: +55-16-633-0136. E-mail: hbettiol@fmrp.usp. br / manegut@rocketmail.com.br
}

altura) é baixa ou moderada (5\%). $\mathrm{Na}$ África e na Ásia, esta é alta ou muito alta (1).

No Brasil, grandes investimentos têm sido dirigidos para a assistência nutricional de crianças de até 5 anos de idade. Estes investimentos têm como objetivos controlar a desnutrição e promover a assistência integral à saúde da criança. Os programas de suplementação alimentar (PSA) (2), que fazem parte de uma prática de política redistributiva, em que o governo adquire determinados produtos e os redistribui gratuitamente para a população (3), são o ponto principal dessas ações. Os PSA são extensiva e historicamente praticados nos centros de saúde das secretarias estaduais de saúde e em outros órgãos institucio- nais. Contudo, eles são um recurso limitado e de difícil operacionalização, principalmente pelo excessivo tecnicismo que encerram e pela diversidade e extensão dos problemas sociais que pretendem mitigar (4-6). Os PSA são, também, freqüentemente utilizados como instrumentos políticos. Nesses casos, a terapêutica individual da desnutrição é confundida com assistência social da família da criança desnutrida e suplementação alimentar propriamente dita.

A não preocupação com a eficiência desses programas se torna evidente pela ausência de procedimentos de avaliação e pela ausência de interação com outras medidas complementares (por exemplo, aquisição e preparo da alimentação cotidiana, tratamento do- 
miciliar de água, manejo do lixo, manutenção e conservação do sistema de saneamento e esgotamento sanitário, planejamento familiar, utilização dos serviços sociais e de saúde) ou educativas, como a assistência em puericultura (isto é, visitas periódicas e rotineiras das crianças às unidades básicas de saúde para fins de orientação quanto a cuidados básicos de alimentação, vigilância do estado nutricional, crescimento e desenvolvimento e medidas preventivas). Esta falta de preocupação leva, por um lado, à homogeneização das intervenções; por outro lado, transforma as intervenções em ações demagógicas (3).

A falta de critérios para a avaliação do estado nutricional das crianças inscritas em programas de suplementação alimentar limita o acompanhamento das mesmas. Conseqüentemente, limita-se o impacto dos PSA sobre as crianças, assim como os benefícios que essas ações poderiam estar proporcionando por si próprias. Esta falta de critérios impossibilita, portanto, a otimização e o redirecionamento desses programas. Também não se sabe como são usados os alimentos fornecidos, o que, por sua vez, impossibilita a avaliação dos objetivos dos PSA - ou seja, não se sabe se os objetivos estão efetivamente sendo atingidos, ou quais são os fatores impeditivos.

Como os PSA são programas extensivos de intervenção e têm alto custo, é oportuno questionar se a suplementação alimentar, tal como é praticada, contribui para a recuperação nutricional ou para a manutenção do crescimento das crianças assistidas que vivem com suas famílias - nos casos em que a suplementação alimentar é utilizada como medida exclusiva, contextualizada nas condições sociais das famílias que dela se beneficiam.

O objetivo do presente trabalho é verificar até que ponto um PSA desenvolvido em Guariba, Brasil, contribuiu para o crescimento das crianças beneficiadas. Além disso, o estudo propõe um método para avaliar o impacto das ações de suplementação alimentar sobre o estado nutricional e sobre o crescimento das crianças assistidas.

\section{MATERIAIS E MÉTODOS}

O presente trabalho foi realizado no município de Guariba, localizado na região nordeste do estado de São Paulo, Brasil. O município possui $264 \mathrm{~km}^{2}$ de área, dos quais aproximadamente $262 \mathrm{~km}^{2}$ são destinados à produção de cana-de-açúcar. Nesta área também está instalado o parque industrial do município. A produção e comercialização de álcool e açúcar são a base da economia local. Estas atividades ocupam aproximadamente $92 \%$ das terras férteis e aglutinam $83 \%$ da população economicamente ativa (7). Em 1980, o município de Guariba tinha 18893 habitantes e, em 1992, 28743 habitantes. Este crescimento demográfico decenal foi devido à migração rural-urbana de trabalhadores diaristas de baixa renda (bóias-frias) (8), motivada principalmente pela expansão da monocultura de cana-deaçúcar (9).

A cidade dispõe de apenas um centro de saúde, da Secretaria de Estado da Saúde (SES). Neste centro de saúde, desde 1986, desenvolve-se um PSA, segundo o modelo proposto pelo Ministério da Saúde (10). As crianças matriculadas nesse PSA recebem mensalmente 30 cupons para troca por leite pasteurizado (tipo $\mathrm{C}-3,3 \mathrm{~g} \%$ de proteínas e $65 \mathrm{kcal} / 100 \mathrm{ml}$ ), segundo os critérios definidos nas normas para o acompanhamento do crescimento e desenvolvimento da criança (11-13). Esses cupons são, presumivelmente, trocados por leite no comércio local.

\section{Grupo de estudo}

Em agosto de 1992, 580 crianças estavam matriculadas no PSA em Guariba. Foram excluídas deste estudo as crianças cujos prontuários não continham informações completas (4\%) e as crianças que haviam abandonado o programa por qualquer motivo ou que estavam faltosas havia mais do que 3 meses (15\%). Portanto, 469 (81\%) crianças, cujos prontuários continham informações completas, foram selecionadas para esta pesquisa (amostragem por conveniência). As informações buscadas no prontuário incluíam: nome, sexo, endereço, data do nascimento, idade na inscrição ao programa, registro das freqüências, registro das consultas e intercorrências médicas e registro mensal de peso e comprimento.

As crianças selecionadas foram subdivididas em quatro grupos, conforme o tempo de freqüência no PSA: o grupo 1 incluía crianças que freqüentavam o programa há até 12 meses; o grupo 2 incluía crianças que freqüentavam o PSA entre 12 e 24 meses; o grupo 3 incluía crianças freqüentadoras entre 24 e 36 meses; e o grupo 4 incluía crianças com freqüência maior do que 36 meses. Os familiares das crianças foram entrevistados por uma única assistente social, no centro de saúde ou na própria residência.

Para os cálculos dos percentis de peso por idade, altura por idade e peso por altura, foi utilizado o programa American Statistics Package (ASP) do National Center for Health Statistics (NCHS) (14). Para o estudo das mudanças do estado nutricional, cada criança foi classificada como acima ou abaixo do $10^{\circ}$ centil da referência, de acordo com os percentis observados de peso por idade, altura por idade e peso por altura $(14,15)$. Os percentis de peso e altura por idade e sexo, assim como de peso por altura, foram calculados: a) no dia da inscrição no programa (matrícula); e b) a partir dos registros de peso e altura da última participação no programa, imediatamente anterior ao dia do registro dos dados (avaliação). Portanto, foram realizadas duas avaliações para cada grupo, a primeira antes de qualquer participação no PSA e outra no final de cada período considerado (modelo transversal). Para avaliação do estado nutricional foram adotados os critérios propostos por Seoane e Lathan (15). As mudanças individuais observadas foram analisadas pelo método de McNemar para nível de significância de $P=0,05$ (16).

O perfil antropométrico foi definido a partir da distribuição das freqüências acumuladas dos percentis observados de peso por idade, altura por idade e peso por altura (sexos combi- 
nados). As distribuições foram comparadas com curvas de distribuições de referência, definidas pela variabilidade esperada para os respectivos percentis em uma população normal. As curvas que representam o perfil antropométrico de cada grupo de estudo foram traçadas a partir da distribuição das freqüências acumuladas dos percentis observados de peso e altura por idade, assim como de peso por altura (sexos combinados), em cada ocasião (matrícula e avaliação). Estas distribuições foram comparadas com curvas de referência (teóricas) definidas pelos autores, calculadas a partir da variabilidade esperada para cada percentil em uma população de crianças consideradas "antropometricamente normais", segundo as referências do NCHS, aplicando-se as propriedades aditivas das medianas (17). Para o cálculo da variabilidade esperada, atribuiu-se uma variação percentual constante para cada percentil, equivalente a $\pm 43,31 \%$, correspondente $\mathrm{a} \pm 1,5$ escores $Z$, sob a distribuição normal gaussiana, estabelecendo assim seus limites (inferior e superior) e, conseqüentemente, os critérios de normalidade. Destas curvas, foram calculadas as respectivas equações polinomiais (de quarto grau, $\mathrm{Y}=\mathrm{A} 0+\mathrm{A} 1 \mathrm{x}+\mathrm{A} 2 \mathrm{x}^{\wedge} 2+$ $\left.\mathrm{A} 3 \mathrm{x}^{\wedge} 3+\mathrm{A} 4 \mathrm{x}^{\wedge} 4\right)$, cujas constantes são apresentadas na tabela 1 .

\section{RESULTADOS}

\section{Aspectos sociodemográficos das famílias das crianças participantes}

Eram procedentes de outros municípios do estado de São Paulo 68\% (319/469) das famílias; de Minas Gerais, $18 \%$ (83/469); da Bahia, 4,5\% (21/469); e dos outros estados, $10 \%$ (46/469). Quanto ao tempo de residência, $27 \%$ das famílias $(127 / 469)$ residiam no local há menos de 1 ano; $24 \%$ $(111 / 469)$, de 2 a 3 anos; $23 \%$ (107/ 469), de 3 a 4 anos, e 25\% (117/469), há mais do que 3 anos. Apenas uma família era natural do município, onde residia há mais de 20 anos. Em 1\% dos casos (6/469) essa informação não estava disponível.

TABELA 1. Parâmetros das curvas de referência, programa de suplementação alimentar, Guariba (São Paulo), Brasil, 1992

\begin{tabular}{|c|c|c|c|c|}
\hline \multirow[b]{2}{*}{ Parâmetros ${ }^{a}$} & \multicolumn{2}{|c|}{ Limite superior } & \multicolumn{2}{|c|}{ Limite inferior } \\
\hline & Valores & Desvio padrão & Valores & Desvio padrão \\
\hline A0 & $-0,63378478$ & 0,79097 & $-0,57016719$ & 0,80815 \\
\hline $\mathrm{A} 1$ & 0,19983499 & 0,15044 & 0,86065069 & 0,15371 \\
\hline $\mathrm{A} 2$ & $-0,006498739$ & 0,00693 & $-0,01934147$ & 0,00693 \\
\hline A3 & $-1,472616 \mathrm{E}-4$ & 0,00011 & 3,3757694E-4 & 0,00011 \\
\hline A4 & 1,1360874E-6 & $5,1985 \mathrm{E}-7$ & $-1,2905637 \mathrm{E}-6$ & $5,3113 \mathrm{E}-7$ \\
\hline
\end{tabular}

${ }^{a}$ Constantes das equações polinomiais.

As famílias eram constituídas por 4,8 pessoas em média; $84 \%(393 / 469)$ eram famílias nucleares; $11 \%(52 / 469)$ das crianças viviam unicamente com a mãe; as demais, com avós, tios, ou outros não familiares. Dentre os responsáveis pelas crianças que participaram no estudo, 37\% (174/469) eram amasiados, solteiros, desquitados ou em situação não definida.

Quanto à idade, $11 \%(54 / 469)$ das mães eram menores de 20 anos; $60 \%$ (280/469) tinham entre 20 e 30 anos; $14 \%(65 / 469)$, entre 30 e 35 anos; $12 \%$ (55/469) tinham idade igual ou maior do que 35 anos. Três por cento (15/ 469) não informaram a idade. Entre os pais, $2 \%(8 / 469)$ eram menores de 20 anos; $44 \%$ (206/469) tinham entre $20 \mathrm{e}$ 30 anos; 20\% (92/469) tinham entre 30 e 35 anos; 21\% (99/469) tinham 35 anos ou mais; e 14\% (64/469) não informaram a idade.

Quanto à escolaridade das mães, $53 \%(249 / 469)$ eram analfabetas ou tinham primário incompleto (menos do que 4 anos de estudo); $27 \%$ (127/469) tinham escolaridade primária completa (4 anos de estudo); 4\% (18/469) tinham escolaridade intermediária (de 4 a 8 anos de estudo, até ginasial completo); 16\% (75/469) não informaram.

Quanto à renda per capita, 29\% (137/ 469) apresentavam renda inferior a 0,25 salários mínimos (SM); 49\% (232/ $469)$, de 0,25 a $0,5 \mathrm{SM} ; 19 \%(87 / 469)$, de 0,5 a 1,0 SM; e os demais $3 \%(13 / 469)$ tinham renda maior do que $1,0 \mathrm{SM}$ por indivíduo (um salário mínimo equivale a, aproximadamente, 105 dólares).

As medianas das idades nos quatro grupos de freqüência, por ocasião da inscrição, foram idênticas $\chi^{2}=0,475, P=$
0,9243 ) e os grupos eram comparáveis entre si $\chi^{2}=8,0, P=0,051$ ) (tabela 2).

\section{Avaliação do perfil antropométrico}

No grupo 1, na matrícula, $66 \%$ das crianças estavam abaixo do 10 o percentil de altura por idade e $71 \%$ estavam abaixo do $10^{\circ}$ percentil de peso por idade (figura 1A). Não foi observado qualquer impacto significativo sobre o perfil da altura por idade após cinco participações (mediana $=5,2$; $\left.\chi^{2}=2,28 ; P>0,05\right)$ (ver tabela 2). As mudanças individuais de peso por idade, no entanto, foram significativas $\left.\chi^{2}=24,64 ; P<0,05\right)$ e suficientes para adequar o perfil de peso por altura $\chi^{2}=11,76, P<0,05$ ) (figura 1B).

Para o grupo 2, na inscrição, 60\% das crianças apresentavam percentis de altura por idade menores do que o 10 o centil; e $65 \%$ das crianças apresentavam percentis de peso por idade menores do que o $10^{\circ}$ centil. O perfil caracterizava as crianças como cronicamente desnutridas (figura 2A). Após 12 a 24 participações (mediana $=16,0$ ), houve mudanças individuais de peso e altura por idade $\chi^{2}=10,66$ e 8,1 , respectivamente; $P<0,05)$ e de peso por altura $\left.\chi^{2}=10,0, P<0,05\right)$, sem que o perfil do grupo se alterasse como um todo, quando comparado com seu perfil na matrícula (figura 2B).

O grupo 3, na inscrição, apresentou um perfil de peso por altura característico de desnutrição crônica de longa duração (figura 3A). Após 24 a 36 participações (mediana $=29,0$ ) houve mudanças individuais significativas, tanto do peso $\chi^{2}=5,48$ ) como da altura por 
TABELA 2. Distribuição das crianças conforme idade no programa de suplementação alimentar, Guariba (São Paulo), Brasil, 1992

\begin{tabular}{|c|c|c|c|c|c|c|c|c|c|}
\hline \multirow[b]{3}{*}{ Grupo } & \multirow[b]{3}{*}{ No. } & \multirow[b]{3}{*}{$\%$} & \multirow[b]{3}{*}{$\mathrm{m} 1^{\mathrm{a}}$ (meses) } & \multicolumn{6}{|c|}{ Idade (meses) } \\
\hline & & & & \multicolumn{3}{|c|}{ Inscrição } & \multicolumn{3}{|c|}{ Avaliação } \\
\hline & & & & Idade mínima & $\mathrm{m} 2^{\mathrm{b}}$ (meses) & Idade máxima & Idade mínima & $\mathrm{m}^{\mathrm{c}}$ (meses) & Idade máxima \\
\hline 2 & 124 & 26 & 16 & 0,59 & 11,7 & 42 & 14,9 & 29 & 59,3 \\
\hline 3 & 102 & 22 & 29 & 0,95 & 10,3 & 27 & 26,6 & 39 & 53,3 \\
\hline 4 & 93 & 20 & 46,4 & 0,23 & 9 & 22,8 & 37,9 & 53,2 & 60,8 \\
\hline
\end{tabular}

${ }^{\mathrm{a}} \mathrm{m} 1$ = mediana de tempo de participação.

${ }^{\mathrm{b}} \mathrm{m} 2=$ mediana das idades na inscrição.

${ }^{\mathrm{c}} \mathrm{m} 3=$ mediana das idades na avaliação.

idade $\left.\chi^{2}=4,33\right)$, sem que o perfil de peso por altura fosse alterado significativamente $\chi^{2}=0,926$ ). Ou seja, o grupo manteve as mesmas características observadas na matrícula (figura 3B).

O grupo 4, tal como o grupo anterior, também apresentava um perfil de comprometimento proporcional de peso e altura por idade e, conseqüentemente, de peso por altura, no limite esperado, por ocasião da inscrição. Após 36 ou mais participações, não foram observadas mudanças individuais significativas de peso por idade $\chi^{2}=$ 0,090), altura por idade $\left.\chi^{2}=0,95\right)$ e peso por altura $\left.\chi^{2}=1,190\right)$. Não houve mudanças no perfil do grupo.

\section{DISCUSSÃO}

A eleição de uma curva padrão para o perfil antropométrico, definida teoricamente, calculada a partir da variabilidade esperada dos percentis de uma população "antropometricamente normal" de crianças, ou seja, uma distribuição simétrica, considerando os limites de normalidade para a variabilidade de peso por idade, estatura por idade e peso por estatura, correspondentes a 1,5 escores $Z$, é o fundamento do método apresentado para avaliação do PSA. É um método original que tem a vantagem de facilitar o acompanhamento periódico dessas crianças e a finalidade de simplificá-lo, sem a necessidade de cálculos estatísticos ou matemáticos, ou de equipamentos computacionais; basta que se projete a freqüência observada com que cada percentil aparece no grupo de estudo, ou sua distribuição intervalar, em cada uma das avaliações e que se comparem as mudanças ocorridas no inter-

FIGURA 1. Perfil antropométrico do grupo 1 por ocasião da matrícula no programa de suplementação alimentar (A) e na avaliação (B), sexos combinados, Guariba (São Paulo), Brasil, 1992
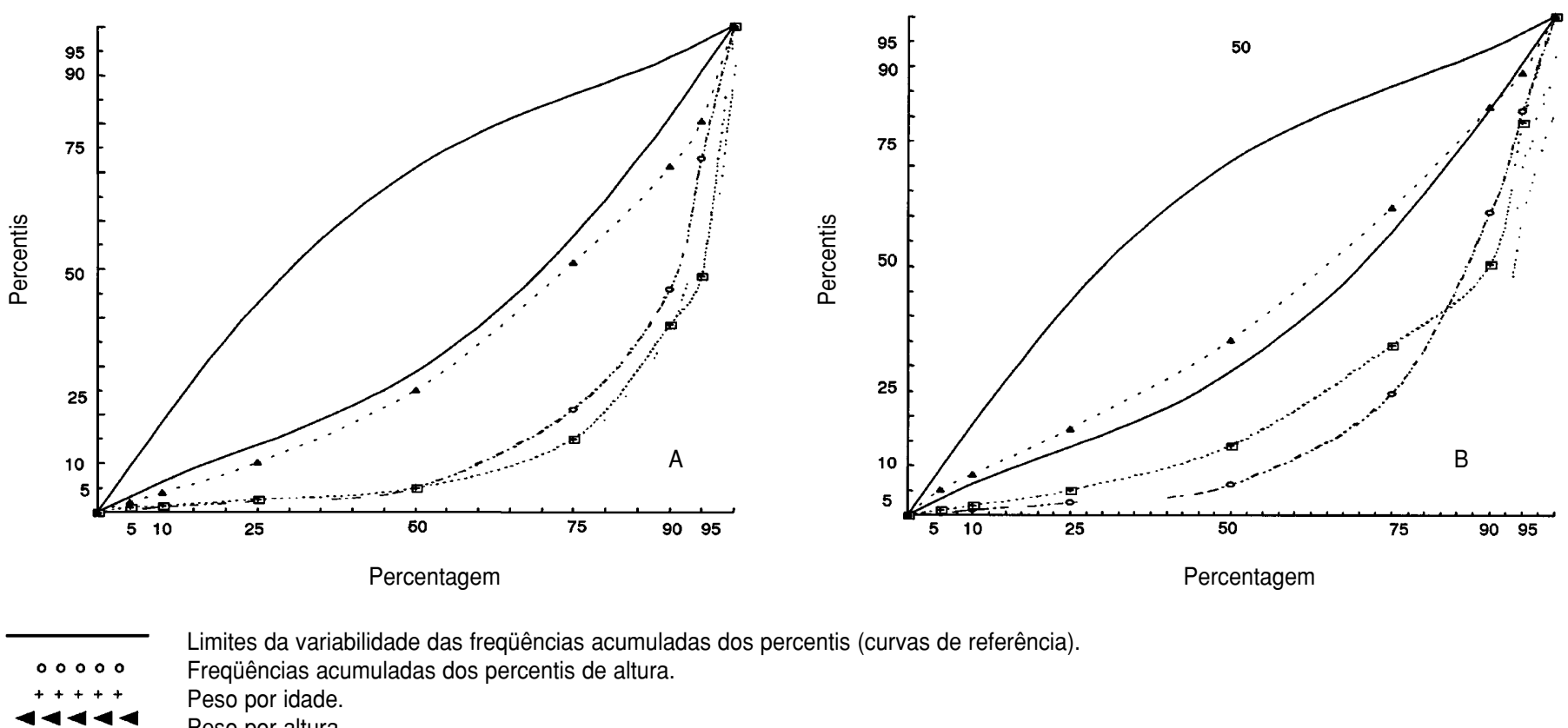

Limites da variabilidade das freqüências acumuladas dos percentis (curvas de referência).

Freqüências acumuladas dos percentis de altura.

Peso por idade.

Peso por altura. 
FIGURA 2. Perfil antropométrico do grupo 2 por ocasião da matrícula no programa de suplementação alimentar (A) e da avaliação (B), sexos combinados, Guariba (São Paulo), Brasil, 1992
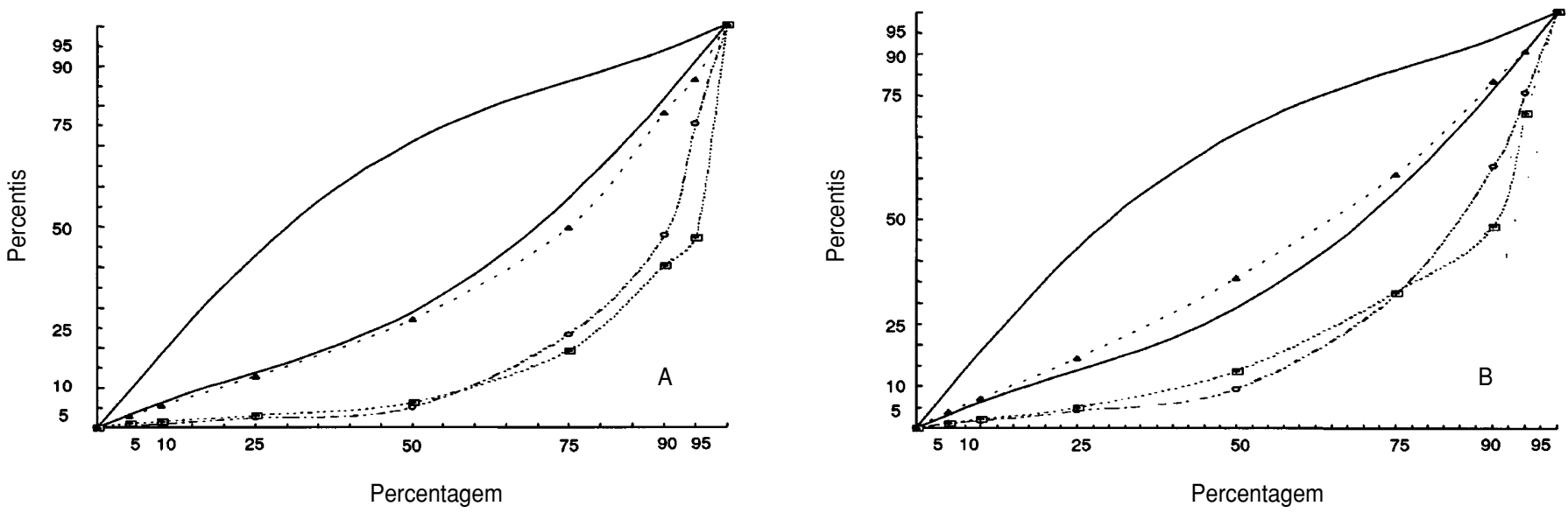

00000

$++++$

Limites da variabilidade das freqüências acumuladas dos percentis (curvas de referência).

Freqüências acumuladas dos percentis de altura.

Peso por idade.

Peso por altura.

FIGURA 3. Perfil antropométrico do grupo 3 por ocasião da matrícula no programa de suplementação alimentar (A) e da avaliação (B), sexos combinados, Guariba (São Paulo), Brasil, 1992
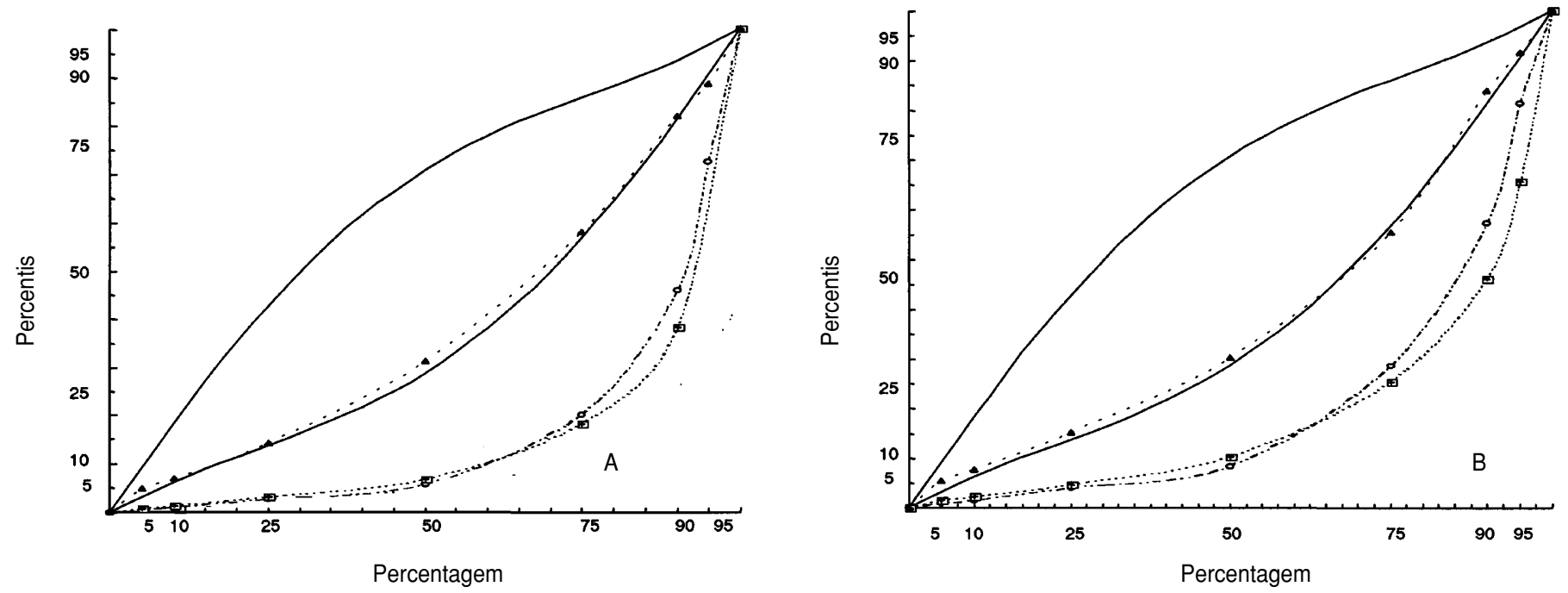

00000

$++++$

$4<4<$

Limites da variabilidade das freqüências acumuladas dos percentis (curvas de referência).

Freqüências acumuladas dos percentis de altura.

Peso por idade.

Peso por altura.

valo de tempo entre elas - tanto para grupos de crianças desnutridas como para crianças nutricionalmente normais ou obesas. Desta forma, o método oferece ao profissional envolvido na atenção primária um método prático, simples e eficaz para avaliar seus grupos de estudo.

A principal característica da coorte analisada era ser constituída por crian- ças severamente desnutridas, filhas de trabalhadores bóias-frias, com baixa renda familiar, e de mães que, em sua maioria, eram analfabetas ou tinham escolaridade primária. O perfil socio- 
econômico não se alterou substancialmente durante o período da análise. Essa estreita correlação da desnutrição com posição da ocupação do chefe da família, renda e escolaridade materna está bem demonstrada na literatura (18-22). Por outro lado, o tempo de residência no local refletia a alta mobilidade espacial (migração interna) das famílias, devida à alternância dos períodos de produção e corte da cana-deaçúcar (51\% residiam no município há menos de 3 anos).

As crianças dos grupos 1 e 2, mais recentes no PSA, apresentavam um perfil antropométrico de crianças cronicamente desnutridas e apresentavam maior comprometimento relativo do peso do que da altura para a idade (figuras 1A e 2A); ou seja, apresentavam um perfil antropométrico correspondente a emaciação e atrofia (23). Esses dois grupos também continham algumas crianças mais velhas (idade máxima de 56,2 meses para o grupo 1 e de 42,0 meses para o grupo 2) e perfil mais desfavorável por ocasião da matrícula. Após os respectivos períodos de suplementação, houve significativa recuperação do peso e, conseqüentemente, observou-se uma adequação do peso para a altura (figuras 1B e 2B), o que refletiu o efeito terapêutico imediato da suplementação. Contudo, o perfil de altura por idade não foi alterado (as recuperações individuais não se refletiram no grupo como um todo).

$\mathrm{Na}$ inscrição, os grupos 3 e 4 também evidenciaram alta prevalência de peso e altura baixos para a idade, porém com peso adequado para a altura (desnutrição crônica de longa duração), o que os diferenciou dos grupos anteriores (figuras 3A e 4A). Na avaliação observou-se que os perfis dos grupos 3 e 4 não se alteraram (figuras 3B e 4B). A manutenção do perfil do grupo 3 pode ser atribuída à suplementação; no grupo 4 não foram observadas mudanças significativas do perfil em relação à inscrição (embora houvesse uma aparente piora do peso em relação à altura para algumas crianças nos percentis mais altos). Os grupos 3 e 4 eram mais homogêneos em relação à idade por ocasião da inscrição. O prolongado período de fre- qüência no PSA faz pressupor que essas crianças, além de desenvolverem maior atividade física, presumivelmente também tiveram alguma mudança na composição e estrutura familiar (aumento do número de irmãos, abandono do chefe da família em conseqüência da migração, variações ou perdas nos rendimentos, etc.). Isto permite deduzir que a suplementação (finalidade em si do PSA) foi suficiente para evitar maiores agravos nutricionais, impossíveis de serem avaliados, para a maioria dessas crianças. De acordo com os parâmetros utilizados no presente estudo, não houve recuperação da altura por idade em nenhum dos grupos; talvez a quantidade de leite fornecido não tenha sido suficiente para promover esta recuperação nos grupos 3 e 4 (pela maior necessidade em função da idade), ou talvez o suplemento não foi adequadamente utilizado (efeito redistributivo).

No entanto, o PSA, tal como praticado, funcionou para adequar o peso para a altura nos grupos 1 e 2, ou seja, funcionou para promover adequação funcional; e para manter a adequação funcional nos grupos 3 e 4 . Não houve evidências de recuperação da altura, mesmo entre as crianças que freqüentaram o programa por mais do que 2 ou 3 anos. Como demonstram seus perfis, estas crianças não recuperaram peso suficiente para que a altura pudesse ser recuperada, como observa Waterlow (24). Estes resultados são semelhantes aos observados por Martorell (25) e Heikens (26), mesmo quando são controladas as variáveis de confusão envolvidas na destinação do leite (como o efeito redistributivo, adições ou diluições, ou troca dos cupons por outros produtos), ou quando são levadas em conta outras circunstâncias, como qualidade e quantidade dos demais alimentos utilizados pelas famílias.

Considerando que, quanto à morbidade, as crianças com peso adequado para a altura diferenciam-se muito pouco das crianças com peso e altura normais para a idade, pode-se especular que, neste sentido, o PSA promoveu algum benefício coletivo (27-30). Nesse limite, como ação de política local, o PSA representou um importante recurso terapêutico de emergencia para as crianças dos grupos 1 e 2 e, também, um recurso institucional para a manutenção do estado nutricional das crianças dos demais grupos, tal como observado por Schilling et al. (6).

Embora os programas de suplementação alimentar sejam freqüentes nos países em desenvolvimento, muitas vezes falham em demonstrar impacto sobre o crescimento infantil, possivelmente porque tendem a atingir crianças mais velhas (31). Em Uganda, Vella et al. (32) investigaram em que idade a chance de recuperação nutricional é maior e observaram uma probabilidade de recuperação semelhante através de todos os grupos etários menores de 5 anos. Conforme estes autores, a probabilidade de recuperação esteve mais associada à educação materna do que à renda.

Entre crianças da área rural da Guatemala, a suplementação esteve associada a ganhos adicionais em peso e altura nos 2 primeiros anos de vida; entre 24 e 36 meses de idade, a suplementação alimentar só teve impacto significativo na altura; e não teve impacto no crescimento entre 3 e 7 anos de idade. Esses resultados coincidiram com as idades em que as velocidades de crescimento, bem como os déficit de crescimento, são maiores nessa população (31).

Em nosso estudo, a variabilidade da idade na matrícula no PSA foi grande (tabela 2); a maior variabilidade foi observada nos grupos 1 e 2, onde havia algumas crianças de maior idade. Possivelmente essa dispersão das idades de entrada no PSA contribuiu para limitar a eficácia do programa em promover a recuperação nutricional das crianças como grupo, pois, para as crianças mais velhas, o melhor momento para recuperação do processo de crescimento já havia ocorrido.

Em amostra de crianças severamente desnutridas na Guatemala, os determinantes do risco de desnutrição aos 36 meses foram semelhantes àqueles documentados em outras partes do mundo (mães pequenas, baixo nível socioeconômico, altas taxas de diarréia, baixa ingestão calórica nas dietas caseiras); contudo, os determinantes 
FIGURA 4. Perfil antropométrico do grupo 4 por ocasião da matrícula no programa de suplementação alimentar (A) e da avaliação (B), sexos combinados, Guariba (São Paulo), Brasil, 1992
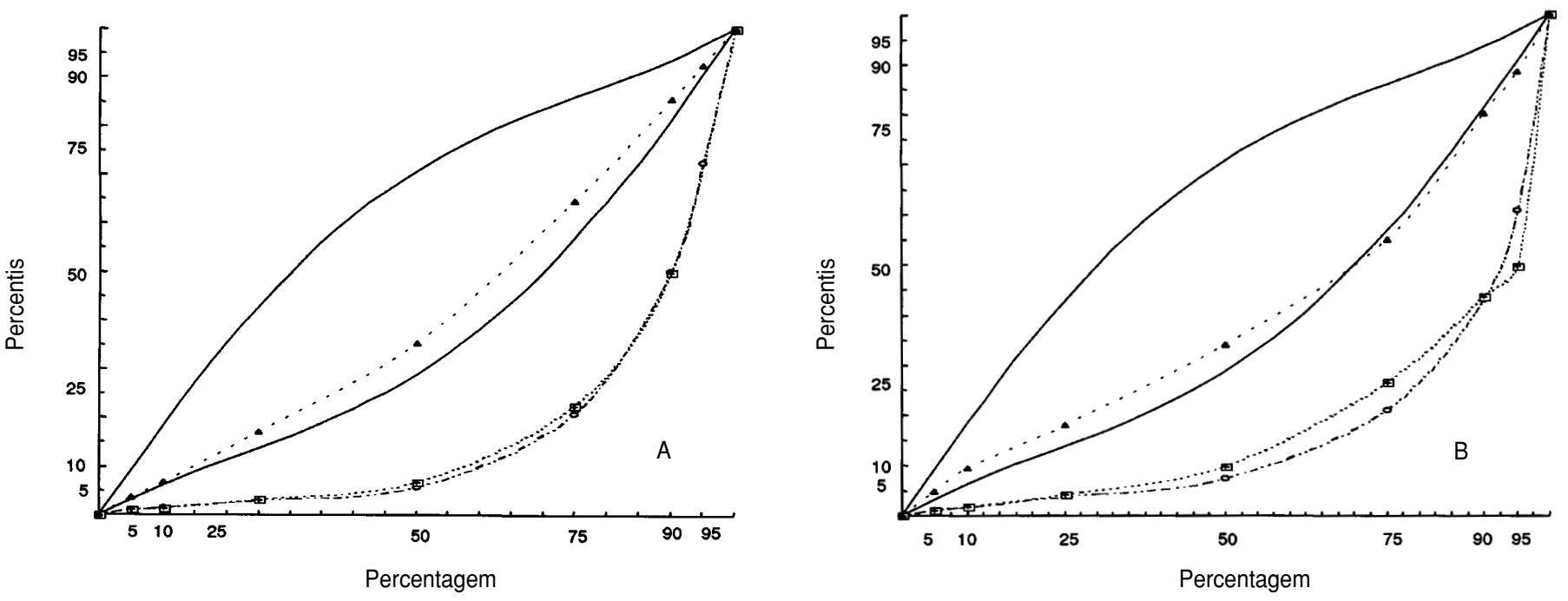

\footnotetext{
Limites da variabilidade das freqüências acumuladas dos percentis (curvas de referência).

Freqüências acumuladas dos percentis de altura.

++++ Peso por idade.

44444 Peso por altura.
}

do benefício diferenciado da suplementação alimentar foram limitados aos indicadores de comprometimento do peso para a idade, do peso para a altura e da circunferência do braço.

Assim, sugere-se que as intervenções nutricionais resultarão em benefícios somente se for possível maximizar a proporção de crianças que responderão bem à intervenção, através do desenvolvimento de indicadores específicos do benefício diferencial da suplementa- ção nutricional, priorizando, portanto, as crianças mais jovens, através do desenvolvimento de critérios específicos (33). Finalmente, a partir de nosso estudo, é possível concluir que os PSA destinados a crianças moderada ou severamente desnutridas necessitam ser periodicamente avaliados. Por um lado, os PSA podem ser eficazes para famílias de renda muito baixa; por outro lado, os PSA podem incorporar fatores que contribuem para a perpe- tuação da desnutrição crônica (dos quais o mais importante é a impossibilidade de ajustar o PSA, em tempo, às necessidades calórico-protéicas das crianças em crescimento, na medida em que o programa é definido por cotas fixas de leite). Isto ocorre principalmente entre as crianças que freqüentam o programa por períodos prolongados (neste estudo, 3 anos ou mais), como também foi observado por Barros et al. entre crianças de idade escolar (34).

\section{REFERÊNCIAS}

1. De Onis M, Monteiro C, Akr J, Glugston G. The worldwide magnitude of protein-energy malnutrition: an overview from the WHO Global Database on Child Growth. Bull World Health Organ 1993;71:703-712.

2. Musgrove P. A avaliação dos programas de alimentação no Brasil: Uma discussão preliminar. Em: Castro CM, Coimbra M (organizadores). O problema alimentar no Brasil. São Paulo: Almed; 1985.

3. Yunes J. Programa de Suplementação Alimentar [documento mimeografado]. São Paulo: Secretaria de Estado da Saúde; 1984.
4. Loyola A. A cultura pueril da puericultura. CEBRAP 1983;2:40-46.

5. Monteiro CA. Saúde e nutrição das crianças de São Paulo: diagnóstico, contrastes sociais e tendências. São Paulo: HUCITEC - EDUSP; 1988.

6. Schilling P. Programa de suplementação alimentar: uma análise crítica. Rev Saude Publ (Sao Paulo) 1990;24:412-419.

7. Fundação SEADE. Demografia - População. Município de Guariba: Sistema SIS - SIM (160101); 1992.

8. D’Incao MC. O bóia-fria: acumulação e miséria. 9a ed. Petrópolis: Vozes; 1983.
9. Fundação Instituto Brasileiro de Geografia e Estatística. IX recenseamento geral do Brasil, 1980: censo demográfico, série regional. Vol 1, no 19, tomo IV. São Paulo: Ministério do Planejamento e Coordenação Geral; 1983.

10. Brasil, Ministério da Saúde e Instituto Nacional de Alimentação e Nutrição. Ações básicas para assistência integral à saúde da criança: acompanhamento do crescimento e desenvolvimento. Brasília: Instituto Nacional de Alimentação e Nutrição; 1984.

11. Monteiro CA. Critérios antropométricos no diagnóstico do estado nutricional e na orientação da 
atividade de recuperação nutricional a nível ambulatorial. São Paulo: Secretaria de Estado da Saúde; 1984.

12. Secretaria de Estado da Saúde. Normas para o acompanhamento do crescimento e desenvolvimento da criança. São Paulo: SES; 1985; Diário Oficial, 21 de março de 1985. (Norma técnica SS 32/85).

13. Secretaria de Estado da Saúde. Critérios para inscrição e acompanhamento na atividade de recuperação nutricional. São Paulo: SES; 1985; Diário Oficial 22 de março de 1985. (Norma técnica SS 33/85).

14. Jordan M. Anthropometric statistical package version 3.1 [programa de computador]. Washington, DC: Division of Nutrition, CHPE (Centers for Disease Control); 1988.

15. Seoane N, Lathan MC. Nutritional anthropometry in the identification of malnutrition in childhood. J Trop Ped Env 1971;17:367.

16. Siegel S. Estatística não paramétrica para as ciências do comportamento. São Paulo: McGraw Hill do Brasil; 1979.

17. Berquó E, Souza J, Gotlieb S. Bioestatística. São Paulo: Editora Pedagógica e Universitária; 1981.

18. Alvim EF. O estudo da nutrição e o desenvolvimento das crianças como indicadores do nível de saúde. Rev Fund SESP 1982;27:1-25.

19. Lima S. Condições socioeconômicas, alimentação e nutrição da população urbana de uma localidade do Estado de Minas Gerais (Brasil). Rev Saude Publica (Sao Paulo) 1989;23:410-421.
20. Monteiro CA, Freitas IC, Baratho RM. Saúde, nutrição e classes sociais: o nexo empírico evidenciado em um grande centro urbano. Rev Saude Publica (Sao Paulo) 1989; 23:422-428.

21. Oliveira LR. Epidemiologia de desnutrição: teoria e prática [tese de doutorado]. São Paulo: Faculdade de Saúde Pública da Universidade de São Paulo; 1989.

22. Victora CG. Epidemiologia da desigualdade. São Paulo: HUCITEC - EDUSP; 1988.

23. Waterlow JC. Classification and definition of protein-calorie malnutrition. Brit Med J 1972; 3:566-569.

24. Waterlow JC. Reflections on stunting. Int Child Health: a digest of current information 1991; 2:25-35.

25. Martorell R, Lechtig A, Yarbrough C, Delgado $\mathrm{H}$, Klein RE. Protein-calorie supplementation and postnatal physical growth: a review of findings from developing countries. Arch Latinoam Nut 1976;26:115-128.

26. Heikens G, Schofield W, Dawson S, McGregor $\mathrm{T}$. The Kingston project: I - Growth of malnourished children during rehabilitation in the community given a high energy supplement. Eur J Clin Nutr 1989;43:145-160.

27. Bairagi R. On the best cut-off point for nutritional monitoring. Am J Clin Nutr 1982;35: 769-770.

28. Seward F, Serdula MK. Infant feeding and infant growth: Task Force on Infant Feeding Practices. Pediatr Suppl 1984;74:728-762.
29. Walker S. Growth in length of children recovering from severe malnutrition. Eur J Clin Nutr 1988;42:395-404.

30. Walker S, Grantham-McGregor S, Powell C, Himes J, Simeon D. Morbidity and the growth of stunted and nonstunted children, and the effect of supplementation. Am J Clin Nutr 1992;56: 504-510.

31. Schroeder DG, Martorell R, Rivera JA, Ruel MT, Habicht JP. Age differences in the impact of nutritional supplementation on growth. $J$ Nutr 1995;125:1051S-1059S.

32. Vella V, Tomkins A, Borghesi JA, Migliori GB, Oryem VY. Determinants of stunting and recovery from stunting in northwest Uganda. Int J Epidemiol 1994;23:782-786.

33. Ruel MT, Habicht JP, Rasmussen KM, Martorell M. Screening for nutrition interventions: the risk or the differential-benefit approach? Am J Clin Nutr 1996;63:671-677.

34. Barros A, Barros M, Maude G, Ross D, Davies $P$, Preece M. Evaluation of the nutritional status of 1st-year school children in Campinas, Brazil. Ann Trop Paediatr 1990;10:75-78.

Manuscrito recebido em 17 de outubro de 1996. Aceito para publicaão em versão revisada em 23 de outubro de 1997.
ABSTRACT

\section{Evaluation of a supplementary
nutrition program \\ Evaluation of a supplementary
nutrition program}

The objective of this study was to evaluate the impact of a feeding supplementation program on the growth of undernourished children younger than 5 years in the city of Guariba, state of São Paulo, Brazil. The sample consisted of 469 malnourished children enrolled in a feeding supplementation program sponsored by the State Health Secretariat. The children were divided into four groups according to how long they had been enrolled in the program: in group 1, the children had been enrolled for up to 12 months; in group 2, from 12 to 24 months; in group 3 from 24 to 36 months; and in group 4 the children had been enrolled for more than 35 months. Percentiles for weight/age, height/age and weight/height were calculated for each child. To assess the impact of the program, reference curves for the anthropometric profile were constructed based on expected variations in population percentiles. The changes observed in each group were analyzed statistically (McNemar). Groups 1 and 2 presented weight recovery and gains in the weight/height ratios for the most severely malnourished children; in group 3, the weight/height ratio was maintained and there was a discrete tendency towards weight recovery, which was reversed in group 4, in which the weight was again low in relation to height. The feeding supplementation program temporarily minimized severe nutritional deficiencies but was not sufficient to recover and maintain normal growth. 